\title{
DERECHO ELECTORAL
}

\section{¿Pueden todos los ciudadanos jóvenes ser electos al Poder Legislativo costarricense?}

\section{Esteban Valverde Esquivel ${ }^{*}$}

Recepción: 10 de setiembre de 2019.

Revisión, corrección y aprobación: 14 de octubre de 2019.

Resumen: El presente estudio se concentra en el requisito etario establecido en el artículo 108 de la Constitución Política para ser electo como diputada o diputado a la Asamblea Legislativa. El análisis gira alrededor del concepto de ciudadanía joven, el que se puede establecer mediante interpretación del artículo 90 de la Constitución Política y la Ley General de la Persona Joven.

Palabras clave: Elecciones de diputado / Requisitos para ser candidato / Representación política / / Persona joven / Juventud / Sufragio pasivo / Poder Legislativo.

Abstract: The study focuses on the age requirement to be eligible to run for congress and which is established in article 108 of the Political Constitution. The analysis zooms in on the concept of young citizenry, which can be established by interpretation of article 90 of the Political Constitution and the General Law on Youth

Key Words: Election of congress members / Requirements for candidates / Political representation / Young person / Youth /Passive suffrage / Legislative Branch.

\footnotetext{
* Costarricense, estudiante, evalverdeesquivel@gmail.com. Estudiante de Bachillerato y Licenciatura en Derecho de la Universidad de Costa Rica. Secretario del Directorio de la Asamblea Nacional de Red Nacional Consultiva de la Persona Joven 2018-2019 y 2019-2020 (ANPJ). Asesor Legislativo de la Asamblea Legislativa de la República de Costa Rica. Becario de la Fundación Konrad Adenauer (KAS). Miembro de la Red Humanista por Latinoamérica (RedHL).
} 


\section{DERECHO EIECTORAL}

"Jóvenes, haced política. Porque si no la hacéis, alguien la hará por vosotros. Y probablemente, contra vosotros".

José Ortega y Gasset

\section{INTRODUCCIÓN}

El poder legislativo en Costa Rica es ejercido por la Asamblea Legislativa quien tiene por delegación del pueblo la potestad de legislar. El artículo 108 de la Constitución Política establece los requisitos para acceder al escaño legislativo: ser ciudadano en ejercicio; ser costarricense por nacimiento o por naturalización con diez años de residencia en el país después de haber obtenido la nacionalidad; y haber cumplido veintiún años de edad.

El análisis del último requisito es el objetivo de este ensayo, donde se examinará la voluntad del constituyente originario y del constituyente derivado, y sus posibles implicaciones en los principios democráticos resguardados por nuestra Carta Magna y la Convención Americana sobre Derechos Humanos; esto a la luz del concepto de ciudadanía joven, que podemos establecer mediante interpretación del artículo 90 de la Constitución ${ }^{1}$, y la ley n. ${ }^{\circ} 8261$, Ley General de la Persona Joven, la cual establece la presunción iuris et de iure, donde todo habitante de la República entre los doce y treinta y cinco años de edad es persona joven².

\footnotetext{
${ }^{1}$ Artículo 90.- La ciudadanía es el conjunto de derechos y deberes políticos que corresponde a los costarricenses mayores de dieciocho años. Reformado el artículo 90 por la Ley N. 4763 de 17 de mayo de 1971, publicada en el tomo II de la Colección de Leyes y Decretos de 1971.

${ }^{2}$ Artículo 2.- Definiciones. Para los efectos de esta Ley, se definen los siguientes conceptos: Adolescente: Persona mayor de doce años y menor de dieciocho años de edad. Comités cantonales de la persona joven. Comisiones constituidas en cada municipalidad del país e integradas por personas jóvenes. Desarrollo integral de la persona joven. Proceso por el cual la persona joven, mediante el ejercicio efectivo de sus derechos y el acceso democrático a las oportunidades que el Estado garantiza por medio de las instituciones un adecuado desarrollo espiritual, social, afectivo, ético, cognoscitivo, físico, moral y material, que la involucre a participar activamente en el desarrollo de la vida nacional y en la identificación y solución de los problemas que la afectan a ella como parte de un grupo social y a la sociedad como un todo. Personas jóvenes. Personas con edades comprendidas entre los doce y treinta y cinco años, llámense adolescentes, jóvenes o adultos jóvenes; lo anterior sin perjuicio de lo que dispongan otras leyes en beneficio de los niños y adolescentes. Sistema Nacional de Juventud. Conjunto de instituciones públicas y privadas, organizaciones no gubernamentales y entidades civiles cuyo objetivo sea propiciar el cumplimiento de los derechos y mayores oportunidades para las personas jóvenes. Sociedad civil. Conjunto de instituciones y organizaciones privadas, organizaciones no gubernamentales, familias y otras organizaciones sociales, establecidas formal o informalmente.
} 


\section{DERECHO ELECTORAL}

\section{Ciudadanía joven, ¿derechos y deberes políticos, INTEgRALes o LIMITADOS?}

La ciudadanía costarricense fue un tema de intenso debate dentro de la Asamblea Nacional Constituyente de 1949, que se concentró en dos extremos: el voto femenino y la edad para adquirir la ciudadanía.

La discusión inició según consta en el acta de sesión n. ${ }^{\circ} 92$ de la Asamblea, con la lectura de la moción presentada por el diputado Gonzalo Ortíz Martín: "la ciudadanía es el conjunto de deberes y derechos políticos que corresponden a los costarricenses, de uno y otro sexo, que hayan cumplido dieciocho años de edad" (Asamblea Legislativa, 2008, p. 355). Dicha redacción coincide a plenitud con el artículo que rige actualmente nuestra Carta Fundamental. Sin embargo, el requisito etario generó adeptos y detractores con diversos tipos de argumentación.

El primer diputado en oponerse a los 18 años de edad fue Álvaro Chacón Jinesta quien, en actas, dijo lo siguiente:

Luego expresó que no estaba con la edad de dieciocho años para poder votar, por cuanto precisamente en esa época nuestros jóvenes cursan la segunda enseñanza, preparándose para obtener su título de bachiller. Si se les permite votar, la política vendrá tan sólo a perjudicarlos en sus propósitos. Por otra parte, significaría llevar la política a los Colegios de Segunda Enseñanza, con los perjuicios del caso. Se va a convertir cada colegio en un campo de batalla político. Propuso que se adoptara la edad de veinte años para sufragar, la más conveniente y adecuada. (Asamblea Legislativa, 2008, p. 355)

De igual forma, lo secundaron los diputados Zeledón Brenes, Jiménez Quesada, González Flores y Dobles Segreda3.

\footnotetext{
${ }^{3}$ Zeledón Brenes: [...] En cuanto a la edad, indicó que la observación del señor Chacón era digna de tomarse en cuenta. Es necesario mantener alejados del turbión de la política a nuestros jóvenes, hasta donde sea indispensable. La edad de los veinte años es la más indicada.

Jiménez Quesada: [...] El segundo observó que nuestro medio era propicio a precipitar al hombre a toda clase de situaciones, lo que resultaba inconveniente. Desde muy jóvenes, tanto los hombres como las mujeres, se inician en la vida de los adultos. Añadió que el oficio del hombre es el más difícil y que amerita a una mayor preparación y madurez mental. Por otra parte, es bien sabido que la edad emotiva por naturaleza es la juventud, la época de la adolescencia, cuando los jóvenes están en pleno desarrollo físico y espiritual, lanzarlos a la política a esta edad, resulta contraproducente.
} 
Por su parte, el diputado Solórzano González defendió la tesis de los 18 años para adquirir la ciudadanía:

También se manifestó de acuerdo con la edad de los 18 años, por cuanto nuestros jóvenes han demostrado un sentido altruista acerca de los destinos del país. [...] también se pronunció de acuerdo con la tesis anterior. Indicó que un joven de dieciocho años sabe qué es lo que le conviene a la República. Además, durante la campaña de Liberación Nacional, los jóvenes fueron al sacrificio conscientes de su patriotismo y de sus deberes. Agregó que los jóvenes de Costa Rica participan en la política con el mayor desinterés, movidos tan solo por sus nobles ideales, lo que representa una ventaja para el país. Además, la misma Constitución del 71 aceptaba la edad de los 18 años para sufragar, sujetándola a dos condiciones: la de ser casado y ser profesor de alguna ciencia. (Asamblea Legislativa, 2008, p. 356)

Lo acompañaron en esta idea los diputados Leiva Quirós, Fournier Acuña y Baudrit Solera ${ }^{4}$.

Al final de la discusión, la moción fue rechazada y los constituyentes se inclinaron por la exigencia de 20 años de edad para obtener la ciudadanía. Por lo que la redacción final del artículo 90 fue la siguiente: "La ciudadanía es el conjunto de derechos y deberes políticos que corresponde a los costarricenses de uno u otro sexo, mayores de veinte años (Asamblea Legislativa, 2008, p. 359).

Gónzalez Flores: [...] Estuvo de acuerdo en prolongar la edad para el ejercicio del sufragio, ya que a los dieciocho años los jóvenes se encuentran en plena adolescencia. A esa edad no se ha alcanzado la madurez mental requerida para ejercer una función fundamental, como es la de emitir el voto. Luego expresó que uno de los grandes prejuicios es el que se refiere a la pretendida precocidad de nuestros jóvenes, en relación con los de otros países, prejuicio muy arraigado y popularizado entre nosotros.

Dobles Segreda: [...] Indicó que la mayoría de las Constituciones han adoptado la edad de los 21 o 22 años para conceder a los ciudadanos el derecho al sufragio con base en que durante esa época el hombre empieza a alcanzar su madurez espiritual".

${ }^{4}$ Baudrit Solera: [...] En lo tocante a la edad de los dieciocho años lo propio ocurriría, sin referirse a otros argumentos, con solo que el pueblo recordase que más de un muchacho inmoló su vida en los campos de batalla, en aras de la libertad de su patria, durante la campaña de Liberación Nacional.

Leiva Quirós: [...] expuso las razones por las cuales estaba de acuerdo con la segunda parte de la moción en debate. Indicó que a los dieciocho años nuestros jóvenes saben perfectamente lo que están haciendo, así como lo que más conviene a los intereses generales del país.

Fournier Acuña: [...] expresó que la realidad era que en Costa Rica los jóvenes adquieren su madurez precozmente. Desde muy temprana edad nuestros muchachos participan activamente en la política. Citó el ejemplo de la gesta del quince de mayo, iniciada por los estudiantes y las mujeres costarricenses. De ahí que esté con la tesis de los dieciocho años. 


\section{DERECHO ELECTORAL}

Sin embargo, 20 años después, en mayo de 1970 el expresidente Daniel Oduber Quirós, en ese momento diputado de la República, presentó una reforma constitucional para bajar a 18 años la edad requerida para la ciudadanía. Dicha reforma responde a lo que años atrás dijo el exrector de la Universidad de Costa Rica, Rodrigo Facio Brenes, y que consta en el dictamen unánime afirmativo del proyecto: "La democracia no es una cosa, sino una forma de vida que necesita constantemente crecer, expandirse y fortalecerse si desea sobrevivir. Para ella, detenerse es rendirse y hacerse rígida es perder su aliento de vida" (Asamblea Legislativa, 1971, p. 15).

Dicha reforma plantea, en su exposición de motivos, la necesidad de dotar a las juventudes costarricenses del derecho a decidir los destinos de la Nación, sustentada en la importante participación de los jóvenes en los movimientos sociales del país, que en su mayoría han liderado, y su determinada convicción de defender la democracia costarricense, su historia y sus conquistas. $Y$ en tono casi poético, el diputado Oduber plasma en su proyecto:

Asimismo, estimamos que en el tanto en que sepamos canalizar bien todas las inquietudes de las nuevas generaciones, así será de beneficioso para el país el estímulo transformador de nuestra juventud; porque una nación que no ofrezca oportunidad de acción a la juventud, tendrá pocas posibilidades de salir de un seguro estancamiento. (Asamblea Legislativa, 1971, p.1).

La ley n. ${ }^{\circ} 4763$ fue aprobada de manera definitiva el 5 de mayo de 1971 en su tercer debate con 46 votos a favor y 4 en contra. Hasta la actualidad, esta redacción es la que rige.

Esta reforma representó un gran avance en la visibilización de las juventudes costarricenses como actores políticos decisivos, en el campo electoral. Empero, es hasta el año 2002, a finales del gobierno Rodríguez Echeverría cuando se aprueba una ley marco que garantiza todos los deberes y derechos de las personas jóvenes, y establece iuris et de iure los rangos de edad de este grupo social -12 a 35 años-. A partir de ese momento, en Costa Rica se empieza hablar de una ciudadanía joven -18 a 35 años-, concepto que Herrera y Muñoz (2008) indican se escapa totalmente del constructo social de ciudadanía impulsado por las teorías liberales y republicanas, limitadas en gran medida a lo político-electoral, y que a partir del siglo XXI exige nuevas interpretaciones desde diferentes perspectivas. 


\section{DERECHO ELECTORAL}

Podemos definir la ciudadanía joven siguiendo el pensamiento de Beck (2006), Luhmann (1998) y Santos (2005), como aquel conjunto de deberes y derechos inherentes a las personas entre los 18 y 35 años, que permiten potenciar la autogestión de su existencia como seres autónomos, y que a su vez impulsan aportes significativos a la sociedad en lo político, lo cultural, lo social y lo económico; al permitir bajo los postulados de la libertad la construcción de su propio futuro.

No obstante, sería iluso, a propósito de este ensayo, afirmar que todos los subsistemas tienen igual preponderancia frente al político. Este último, a lo largo de la historia ha sido de debate central, respecto a las prohibiciones establecidas a diferentes sectores poblacionales; en este caso, personas jóvenes. De tales prohibiciones nuestros constituyentes no se escaparon, empleando una línea argumentativa de debilidad e incapacidad racional de las juventudes para aventurarse en la vida política nacional, y para elegir a sus representantes.

\section{Requisitos Para Ser electa o electo a la Asamblea legislativa}

Los requisitos para acceder a una curul en Cuesta de Moras los establece el artículo 108 de la Constitución Política, y es importante destacar que dicho artículo nunca ha sido reformado por la Asamblea Legislativa, por lo que el espíritu del constituyente originario se mantiene intacto en este.

La discusión sobre los requerimientos para ser legisladores de la República se propició en las sesiones n. ${ }^{\text {os }} 63,64$ y 65, cuando el diputado Facio Brenes presentó junto con sus compañeros de bancada la siguiente moción:

Sobre este artículo se presentaron las siguientes mociones: $1 .^{a}$ ) del grupo Social Demócrata, que dice así: "Artículo 81.- Para ser diputado se requiere: $1 .^{\circ}$ - Ser ciudadano en ejercicio; $2.0^{\circ}$ Ser costarricense por nacimiento o por adopción, con diez años de residencia en el país, después de haber obtenido la nacionalidad; 3.0- Haber cumplido veintiún años de edad; y 4.0- No haber sido condenado por delitos electorales o contra la propiedad, la fe pública o las buenas costumbres". (Asamblea Legislativa, 2008, p. 89).

Dicha moción trajo consigo una discusión entre los constituyentes por tres sesiones consecutivas, donde salieron a relucir importantes disertaciones, las cuales se adherían o rechazaban la idea socialdemócrata de establecer 


\section{DERECHO EIECTORAL}

una edad mínima para ser diputado o diputada de la República; la Asamblea se dividió en tres tesis: establecer un requisito etario de 21 años para la diputación; establecer este requisito, pero aumentar a 25 años la edad requerida; y por último, la tesis de no establecer ninguna edad, ya que el primer inciso del artículo establecía la necesidad de ser ciudadano en ejercicio, y para ingresar a este estatus jurídico era necesario cumplir determinada edad.

Los diputados Baudrit Solera y Vargas Vargas, defensores de la moción socialdemócrata, expresaron lo siguiente:

El primero expresó que por diez años había convivido con jóvenes universitarios, y que se había dado perfecta cuenta que el universitario, aun sin tener los 21 años, tenía absoluta capacidad de juicio. Además, después de la patriótica actitud de los jóvenes de la Universidad, todos los cuales se inscribieron para defender al país, bien merecían poder ser electos diputados a los 21 años. El segundo manifestó que era necesario abrirles oportunidades a los jóvenes para que vinieran a la Cámara. (Asamblea Legislativa, 2008, p. 97).

Por otro lado, el diputado Volio Sancho se opuso a que la edad mínima fuera 21 años, y en un pequeño análisis comparado solicitó aumentar a 25 años el requisito etario para los congresistas, como consta en su disertación:

El Representante VOLIO SANCHO dijo que ratificaba las palabras pronunciadas por sus compañeros en defensa de los intereses de la juventud, exaltando a nuestros jóvenes, especialmente a los universitarios, pero el caso de estos últimos se puede considerar como excepcional. A la Cámara llegan, no los jóvenes universitarios, sino el tipo medio de ciudadano versado en los negocios públicos y con cierta experiencia, para tratar los problemas concernientes a una Asamblea Legislativa. Aclaró que de ninguna manera trataba de empañar las virtudes cívicas de la juventud costarricense al propiciar la tesis de los 25 años. Por el contrario, estaba pronto a apoyar toda medida tendiente a hacerle justicia. Se refirió al hecho de que en el seno de la Comisión Redactora del Proyecto del 49, había propiciado la tesis de que el derecho al sufragio se otorgara a los jóvenes desde los 18 años, como premio a su brillante y patriótica actitud en la campaña de liberación nacional. Sin embargo, una cosa es ejercer el derecho 


\section{DERECHO ELECTORAL}

al voto y otra muy distinta desempeñar facultades legislativas. Agregó que de los 21 países americanos, 10 tienen establecido el requisito de los 25 años, Brasil exige una edad no menor de 35 años. En Costa Rica sólo tres Constituciones-la de 1825, 1844 y 1871-, han establecido una edad mínima de 21 años, con excepción de la Constitución Federal de Centro América, que exigía haber cumplido los 23 años. (Asamblea Legislativa, 2008, p. 100).

Mientras que el constituyente Chacón Jinesta se casó con la idea de no establecer una edad mínima, ya que la exigencia de ser ciudadano ya traía implícita la necesidad de cumplir una mayoría de edad, y era ilógico restringir más el acceso al congreso:

El Representante CHACÓN JINESTA apuntó la observación que en el inciso en debate prácticamente no tenía razón de ser, por cuanto se aprobó un inciso primero que exige, para poder ser electo diputado, ser ciudadano en ejercicio. En Costa Rica la ciudadanía se adquiere a los 20 años, de acuerdo con la Carta del 71, y a los 18 , de acuerdo con el Proyecto del 49 ¿Por qué entonces venir a poner una nueva limitación de edad? Además, si el individuo al adquirir el goce de su ciudadanía puede elegir y ser electo, no se justifica esa nueva limitación de la edad. Insistió en que el inciso significaba una redundancia, por lo que bien podría ser suprimido. (Asamblea Legislativa, 2008, p. 100).

Añadida a la exposición de Chacón Jinesta, el diputado Rojas Vargas esgrimió una especie de híbrido entre los pensamientos de los socialdemócratas y las de los opositores, en favor de imponer un mínimo de edad, pero a su vez que la ciudadanía se obtuviera a los 21 años, contrario a la Constitución del 71 (20 años) y el proyecto de Constitución de la Junta Fundadora (18 años):

El Representante ROJAS VARGAS defendió la tesis de los 21 años. Dijo que había observado que en la mayoría de los países las leyes indican los 21 años para que el individuo adquiera la personalidad plena y, por ende, la ciudadanía, que no es otra cosa que el ejercicio de sus derechos de ciudadano. Añadió que ese principio de que los diputados podrán ser electos a los 21 años, estaba en la Carta del 71 , sin que hubiera provocado dificultad o conflicto. Ese principio, por el contrario, es saludable, porque permite la llegada a las 


\section{DERECHO ELECTORAL}

Cámaras de los jóvenes, que, en la mayoría de los casos, vienen a ser una especie de contralor de las mayorías disciplinadas, como ocurrió en los Congresos últimos. Dijo que ningún perjuicio para la buena marcha del Congreso había ocasionado el principio de la Constitución del 71. Al Congreso han llegado jóvenes que le han prestado al país grandes beneficios. Concluyó diciendo que aceptar la tesis de los 25 años, significaba una afrenta para la juventud estudiosa de Costa Rica, que acaba de dar muestras de su patriotismo en todo el desarrollo de la campaña de liberación nacional. (Asamblea Legislativa, 2008, p. 100).

Estas intervenciones son de sumo valiosas para comprender el espíritu del artículo 108, al final la idea de establecer en 21 años la edad mínima para acceder a la diputación fue aprobada por el plenario con más de la mitad más uno de los votos requeridos. Es importante resaltar que los requisitos para ser diputado o diputada fueron debatidos por la constituyente, 29 sesiones antes de establecer los 20 años como edad necesaria para obtener la ciudadanía costarricense. Al revisar las actas de las sesiones donde se discutió los requerimientos para ser ciudadano costarricense, ni el diputado Chacón Jinesta ni el diputado Rojas Vargas hicieron uso de la palabra para exponer estos mismos argumentos, en el sentido de homologar las edades necesarias para la ciudadanía y el escaño legislativo.

Podemos determinar que el espíritu del constituyente originario es solicitar una edad más avanzada para ser congresista, y conceder de manera parcial los derechos y deberes políticos de los ciudadanos menores a 21 años, al permitir solo el ejercicio del sufragio activo. Y con la reforma de 1971, podríamos decir que el espíritu del constituyente derivado se alineó al pensamiento inicial de la Junta Fundadora de la Segunda República respecto a su proyecto de constitución.

\section{ANÁLISIS CONSTITUCIONAL Y CONVENCIONAL}

El Gobierno de la República de Costa Rica es popular, representativo, participativo, alternativo y responsable. $Y$ es ejercido junto al pueblo por tres poderes: Legislativo, Ejecutivo y Judicial. Desde el artículo noveno de nuestra Carta Magna, podemos constatar cómo nuestros constituyentes apostaron por un sistema político democrático que, muy de la línea de Hernández (1993), busca su fundamento en las elecciones libres, directas y universales, que son legitimadas por los elementos de soberanía popular, 


\section{DERECHO EIECTORAL}

derivada de la idea de autogobierno y primacía de la sociedad sobre el Estado. Participación, como elemento trascendental de la soberanía popular, que de manera directa o indirecta permite a la ciudadanía expresar su voluntad, garantizando el pluralismo político y el respeto por las minorías. Representatividad, como garantía de que los ciudadanos podrán verse representados en ese Gobierno y en sus mandatos; y alternativo, donde las autoridades serán renovadas en períodos determinados para evitar su perpetuidad en el poder, dando sustento constitucional al principio de alternancia en el poder.

Al analizar los artículos 9, 90 y 108 de nuestra Carta Magna, esta restricción al sufragio pasivo de la ciudadanía joven entre los 18 y 20 años de edad, a la Asamblea Legislativa, contraviene la esencia de nuestro sistema político democrático -popular, participativo, representativo, alternativo y responsable-, y desvirtúa este poder del Estado, debido a que en tesis de principio es la representación del pueblo -toda la ciudadanía- como lo manifiesta el artículo $105^{5}$. Sin embargo, no todos los ciudadanos de la República pueden participar como candidatos en elecciones libres, directas y universales por una curul en Cuesta de Moras, por una decisión meramente política que restringe el ejercicio pleno de todos los deberes y derechos políticos que conllevan ser ciudadano de una república.

Por otra parte, en un análisis convencional del Pacto de San José (CADH), podemos encontrar en el artículo 23 de dicho instrumento internacional los derechos políticos inherentes a todos los ciudadanos:

Artículo 23. Derechos Políticos. 1. Todos los ciudadanos deben gozar de los siguientes derechos y oportunidades: a) De participar en la dirección de los asuntos públicos, directamente o por medio de representantes libremente elegidos; b) De votar y ser elegidos en elecciones periódicas auténticas, realizadas por sufragio

\footnotetext{
${ }^{5}$ Artículo 105.- La potestad de legislar reside en el pueblo, el cual la delega en la Asamblea Legislativa por medio del sufragio. Tal potestad no podrá ser renunciada ni estar sujeta a limitaciones mediante ningún convenio ni contrato, directa ni indirectamente, salvo por los tratados, conforme a los principios del Derecho Internacional. El pueblo también podrá ejercer esta potestad mediante el referéndum, para aprobar o derogar leyes y reformas parciales de la Constitución, cuando lo convoque al menos un cinco por ciento (5\%) de los ciudadanos inscritos en el padrón electoral; la Asamblea Legislativa, mediante la aprobación de las dos terceras partes del total de sus miembros, o el Poder Ejecutivo junto con la mayoría absoluta de la totalidad de los miembros de la Asamblea Legislativa. El referéndum no procederá si los proyectos son relativos a materia presupuestaria, tributaria, fiscal, monetaria, crediticia, de pensiones, seguridad, aprobación de empréstitos y contratos o actos de naturaleza administrativa. Este instituto será regulado por ley, aprobada por las dos terceras partes de la totalidad de los miembros de la Asamblea Legislativa. Reformado el artículo 105 por el artículo 1 de la Ley N. 8281 de 28 de mayo de 2002, publicada en La Gaceta N. ${ }^{\circ} 118$ de 20 de junio de 2002.
} 


\section{DERECHO ELECTORAL}

universal e igual y por voto secreto que garantice la libre expresión de la voluntad de los electores, y c) De tener acceso, en condiciones generales de igualdad, a las funciones públicas de su país. 2. La ley puede reglamentar el ejercicio de los derechos y oportunidades a que se refiere el inciso anterior, exclusivamente por razones de edad, nacionalidad, residencia, idioma, instrucción, capacidad civil o mental, o condena, por juez competente, en proceso penal. [Resaltado no es del original].

A primera vista, se observa que el inciso 2) permite a la ley reglamentar estos derechos y oportunidades en diferentes esferas entre ellas la edad, por lo que en principio la misma CADH da luz verde para que los Estados regulen a su placer el requisito etario. Sin embargo, mediante jurisprudencia de la Corte Interamericana de Derechos Humanos (Corte IDH), en los casos Casos Yatama vs. Nicaragua, Castañeda Gutman vs. México y López Mendoza vs. Venezuela, la Corte ha indicado que el artículo 23 debe interpretarse en su integralidad y que las posibles restricciones contempladas en este deben cumplir parámetros de legalidad, finalidad de la restricción, proporcionalidad de la restricción y prevalecimiento de una sociedad democrática (Konrad Adenauer Stiftung, 2014, p. 585).

Bajo los criterios establecidos por la jurisprudencia de la Corte IDH, podríamos visualizar posibles lesiones a los derechos políticos de los ciudadanos costarricenses. En primera instancia, respecto a la reserva de ley para aplicar estas medidas restrictivas, Costa Rica cumple en todos sus extremos, ya que dicha restricción es de orden constitucional; no obstante, en la finalidad que persigue dicha medida, a pesar de que nuestra Constitución es "preconvencional", las actas de la Asamblea Constituyente evidencian que el requisito de 21 años para ser diputado se basó en criterios históricos y adultocéntricos, obviando el principio de igualdad. Añadido a esto, es cuestionable la proporcionalidad de la medida respecto a la exclusión total de las personas entre los 18 y 20 años a participar como candidatos en las elecciones legislativas, y que pertenecen a un segmento poblacional -15 a 24 años-, con proyecciones para el 2020, equivalente a tres cuartos de millón según el INEC (2013); además, según la III Encuesta nacional de juventudes del Consejo de la Persona Joven (2018), el 35,5\% de la población joven se encuentra en el rango etario de los 18 a 24 años; y por último, la primacía de una sociedad democrática, no se cumple en su totalidad al restringir a una fracción de ciudadanos -jóvenes- que conforman el pueblo, siguiendo la línea constitucional, a representar a sus 


\section{DERECHO ELECTORAL}

compatriotas desde el poder que por excelencia es reflejo de la ciudadanía costarricense.

\section{COROLARIO}

Conforme a los elementos expuestos en este ensayo, podemos concluir que los requisitos exigidos para la ciudadanía y para poder ser diputado de la República son una decisión totalmente política con tintes de discrecionalidad y arbitrariedad, de los cuales no se escapan los artículos 90 y 108 de la Constitución, y que son muy difíciles de contener cuando es el poder constituyente originario, invocando la voluntad del soberano, el que establece estas exigencias. De igual forma, estos pueden lesionar los principios básicos del sistema político democrático - popular, participativo, representativo, alternativo y responsable- que resguarda la propia Carta Magna, y la posibilidad de que mediante los postulados interpretativos de la Corte IDH respecto al artículo 23 de la CADH, el artículo 108 violente los derechos políticos inherentes a todos los ciudadanos de la República.

Por otra parte, el país ha dado pasos importantes en el reconocimiento del papel protagónico que ejercen las juventudes en los diversos subsistemas, en especial el político. No obstante, dichos esfuerzos no pueden quedarse únicamente en la reforma constitucional del artículo 90 y la aprobación de la Ley General de la Persona Joven; es necesario eliminar los prejuicios sobre la población joven, de la mano de reformas y nuevas interpretaciones del ordenamiento jurídico, que permitan a todos los ciudadanos jóvenes ejercer a plenitud todos sus derechos y deberes políticos, al representar o ser representados en puestos de toma de decisiones trascendentales para el país, más aún de cara a los 200 años de vida independiente de nuestra Nación, una historia que se ha escrito con tinta joven.

A modo de conclusión, planteo la siguiente interrogante: ¿Quiénes ocuparían la Presidencia y Vicepresidencia de la Asamblea Legislativa, si todas las diputadas y diputados son menores de 30 años? Dicha pregunta, será objeto de análisis en un futuro artículo6.

\footnotetext{
${ }^{6}$ Constitución Política: Artículo 115.- La Asamblea elegirá su Directorio al iniciar cada legislatura. El Presidente y el Vicepresidente han de reunir las mismas condiciones exigidas para ser Presidente de la República. El Presidente de la Asamblea prestará el juramento ante ésta y los Diputados ante el Presidente. Artículo 131.- Para ser Presidente o Vicepresidente de la República se requiere: 1) Ser costarricense por nacimiento y ciudadano en ejercicio; 2) Ser del estado seglar; 3) Ser mayor de treinta años.
} 


\section{DERECHOELECTORAL}

\section{REFERENCIAS BIBLIOGRÁFICAS}

Alexy, R. (1993). Teoría de los Derechos Fundamentales. Madrid: Centro de Estudios Constitucionales.

Beck, U. (2006). La sociedad del riesgo: hacia una nueva modernidad. Barcelona: Paidós Ibérica S.A.

Beck, U. (2006). Hijos de la libertad. México: Fondo de Cultura Económica.

Cascante, M. y Pignataro, A. (2018). Los electorados de la democracia costarricense. Percepciones ciudadanas y participación en torno a las elecciones nacionales de 2014. San José: Editorial IFED-TSE.

Costa Rica (1949) Constitución Política de la República de Costa Rica. Recuperado de http://www.tse.go.cr/pdf/normativa/constitucion.pdf

Costa Rica (2018). Ley General de la Persona Joven. Ley n. ${ }^{\circ} 8261$ del dos del mayo. Publicada en La Gaceta n. ${ }^{\circ} 95$ del veinte de mayo.

Costa Rica. Asamblea Legislativa (1971). Expediente digital, ley $n .^{\circ} 4763$, reforma constitucional al artículo 90 . Recuperado de http://www.asamblea.go.cr/Centro_de_informacion/Consultas_SIL/SitePage s/ConsultaLeyes.aspx

Costa Rica. Asamblea Legislativa de la República de Costa Rica (2008). Actas Asamblea Constituyente 1949, tomo I, II y III. Recuperado de http://www.asamblea.go.cr/sd/Otras_publicaciones/Forms/AllItems.aspx

Costa Rica. Consejo de la Persona Joven (2018). Tercera encuesta nacional de juventudes 2018. Informe de principales resultados. San José: SINART.

Díaz, D. (2008). La fiesta de la independencia en Costa Rica, (1821-1921). San José: EUCR.

Hernández, R. (1993). El Derecho de la constitución. San José: Editorial Juricentro.

Herrera, M. y Muñoz, D. (2008). ¿Qué es la ciudadanía juvenil? Acciones e Investigaciones Sociales, (26), 189-203. Recuperado de https://dialnet.unirioja.es/servlet/articulo?codigo $=2975189$

Fundación Konrad Adenauer Stiftung (Ed.)(2014). Convención Americana sobre Derechos Humanos comentada. Recuperado de http://www.corteidh.or.cr/tablas/30237.pdf 


\section{DERECHO ELECTORAL}

Instituto Nacional de Estadística y Censos (2013). Estimaciones y Proyecciones de Población por sexo y edad 1950-2050. Recuperado de http://www.inec.go.cr/sites/default/files/documentos/poblacion/estimacione s_y_proyecciones_de_poblacion/publicaciones/repoblacev1950-2050-01.pdf

Luhmann, N. (1998). Sistemas Sociales: lineamientos para una teoría general. Barcelona: Anthropos Editorial.

Saborío, R. (2005). Actas de la Asamblea Nacional Constituyente de Costa Rica, 1949. Recuperado de https://www.cesdepu.com/actas/ANC49.pdf

Sáenz, J. (2017). Historia del derecho costarricense. San José: ISOLMA

Santos, B. (1998). De la mano de Alicia. Lo social y los políticos en la postmodernidad. Recuperado

de http://enlaceacademico.ucr.ac.cr/sites/default/files/publicaciones/DE\%20LA \%20MANO\%20DE\%20ALICIA_Boaventura\%20de\%20Sousa.pdf

Santos, B. (2005). Democratizar la democracia: los caminos de la democracia participativa. México: Fondo de Cultura Económica. 